\title{
Ubiquitous Influence of Wildfire Emissions and Secondary Organic Aerosol on Summertime Atmospheric Aerosol in the Forested Great Lakes Region
}

Matthew J. Gunsch ${ }^{1}$, Nathaniel W. May ${ }^{1}$, Miao Wen ${ }^{2}$, Courtney L. H. Bottenus ${ }^{2,3}$, Daniel 5 J. Gardner ${ }^{1}$, Timothy M. VanReken ${ }^{2, \dagger}$, Steven B. Bertman ${ }^{4}$, Philip K. Hopke ${ }^{5,6}$, Andrew P. Ault ${ }^{1,7}$, Kerri A. Pratt ${ }^{1,8}$

${ }^{1}$ Department of Chemistry, University of Michigan, Ann Arbor, MI

${ }^{2}$ Department of Civil and Environmental Engineering, Washington State University, Pullman, WA

${ }^{3}$ Pacific Northwest National Laboratory, Richland, WA

$10 \quad{ }^{4}$ Department of Chemistry, Western Michigan University, Kalamazoo, MI

${ }^{5}$ Center for Air Resources, Engineering and Science, Clarkson University, Potsdam, NY

${ }^{6}$ Department of Public Health Sciences, University of Rochester School of Medicine and Dentistry, Rochester, NY

${ }^{7}$ Department of Environmental Health Sciences, University of Michigan, Ann Arbor, MI

$15{ }^{8}$ Department of Earth and Environmental Science, University of Michigan, Ann Arbor, MI

${ }^{\dagger}$ Now at the National Science Foundation, Arlington, VA

Correspondence to: Kerri A. Pratt (prattka@umich.edu), Andrew P. Ault (aulta@umich.edu) 


\section{Supporting Measurements}

Meteorological data (Figure S1), including wind direction, wind speed, relative humidity, and temperature, were collected by a Vaisala WXT510 weather sensor located at the top of the PROPHET tower. Variations in meteorological conditions throughout the study, and average meteorological conditions during each period of influence, are discussed in the main text. In order to determine the origin of the influential air masses (Figure S2), backward air mass trajectories were calculated using the NOAA Hybrid Single Particle Lagrangian Integrated Trajectory (HYSPLIT) Model (Stein et al., 2015). A final altitude of $500 \mathrm{~m}$ AGL was used for the field site, with each trajectory modeling the proceeding $72 \mathrm{~h}$. During each of the three influence air mass locations, median, was well as $25^{\text {th }}$ and $75^{\text {th }}$ percentile aerosol number, mass, and size distributions were calculated based on SMPS measurements (Figures S3 and S4). Predicted $\mathrm{NH}_{4}{ }^{+}$(Figure S4) was calculated using the methods described by Sueper (2010). Though these calculations indicate the aerosol is likely acidic, there are caveats associated with these calculations, as outlined by Hennigan et al. (2015). Therefore, the $\mathrm{pH}$ cannot be reliably calculated beyond a qualitative indication of whether or not the aerosol is acidic. 


\section{References}

Hennigan, C.J., Izumi, J., Sullivan, A.P., Weber, R.J., Nenes, A., 2015. A critical evaluation of proxy methods used to estimate the acidity of atmospheric particles. Atmos. Chem. Phys. 15, 2775-2790.

Stein, A., Draxler, R., Rolph, G., Stunder, B., Cohen, M., Ngan, F., 2015. NOAA's HYSPLIT atmospheric transport and dispersion modeling system. B. Am. Meteorol. Soc. 96, 20592077.

Sueper, D., 2010. ToF-AMS analysis software. Available at: http://cires1.colorado.edu/jimenezgroup/ToFAMSResources/ToFSoftware/index.html.

VanReken, T., Mwaniki, G., Wallace, H., Pressley, S., Erickson, M., Jobson, B., and Lamb, B.: Influence of air mass origin on aerosol properties at a remote Michigan forest site, Atmos. Environ., 107, 35-43, 2015. 


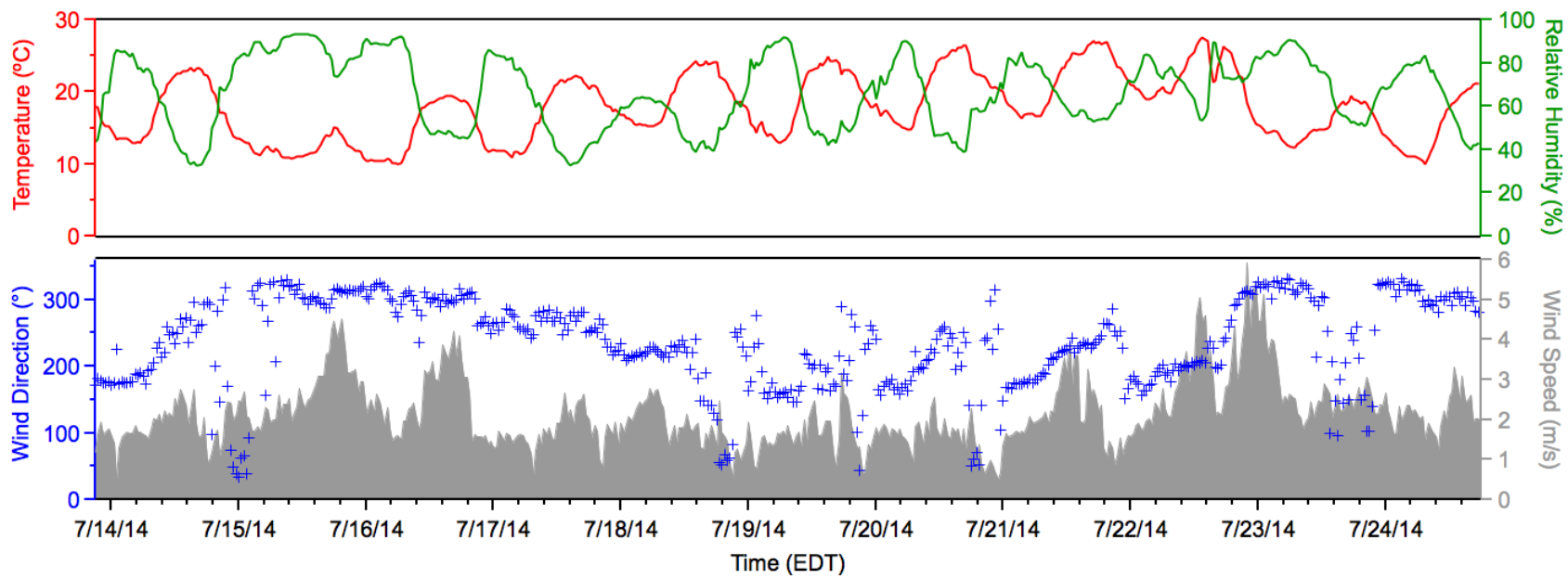

Figure S1. Meteorological conditions measured from a height of $\sim 30 \mathrm{~m}$ at the UMBS PROPHET Tower. 


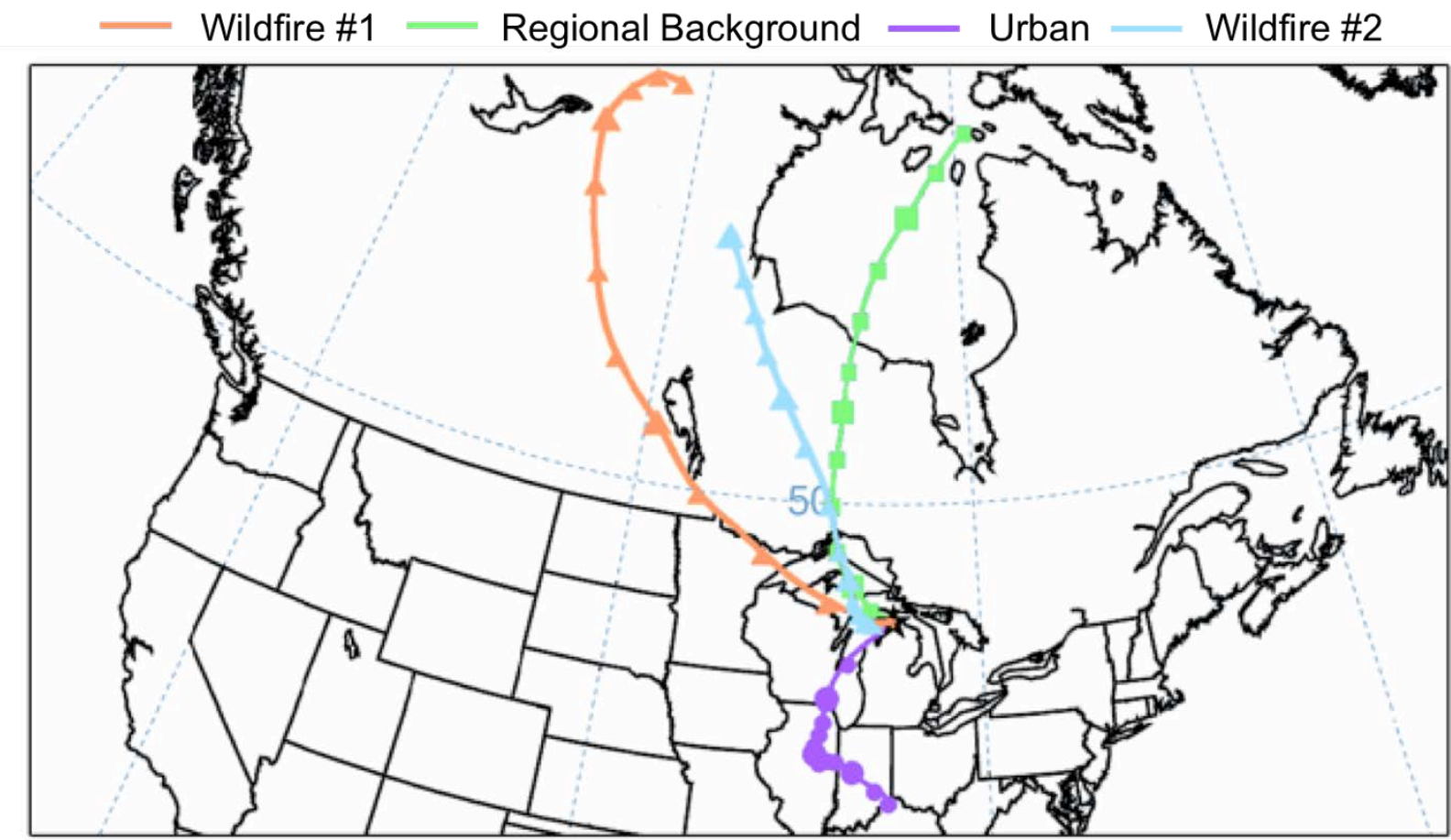

Figure S2. Representative $72 \mathrm{~h}$ HYSPLIT back trajectories with a final altitude of $500 \mathrm{~m}$ for the four air mass influences, with markers indicating $6 \mathrm{~h}$ intervals. Trajectory start times were: Wildfire \#1: 7/14/2014 07:00 EDT, Regional Background: 7/17/2014 07:00 EDT, Urban: 7/21/2014 07:00 EDT, Wildfire \#2: 7/24/14 07:00 EDT. Colors correspond to the air mass of influence indicated in Figure 3. 


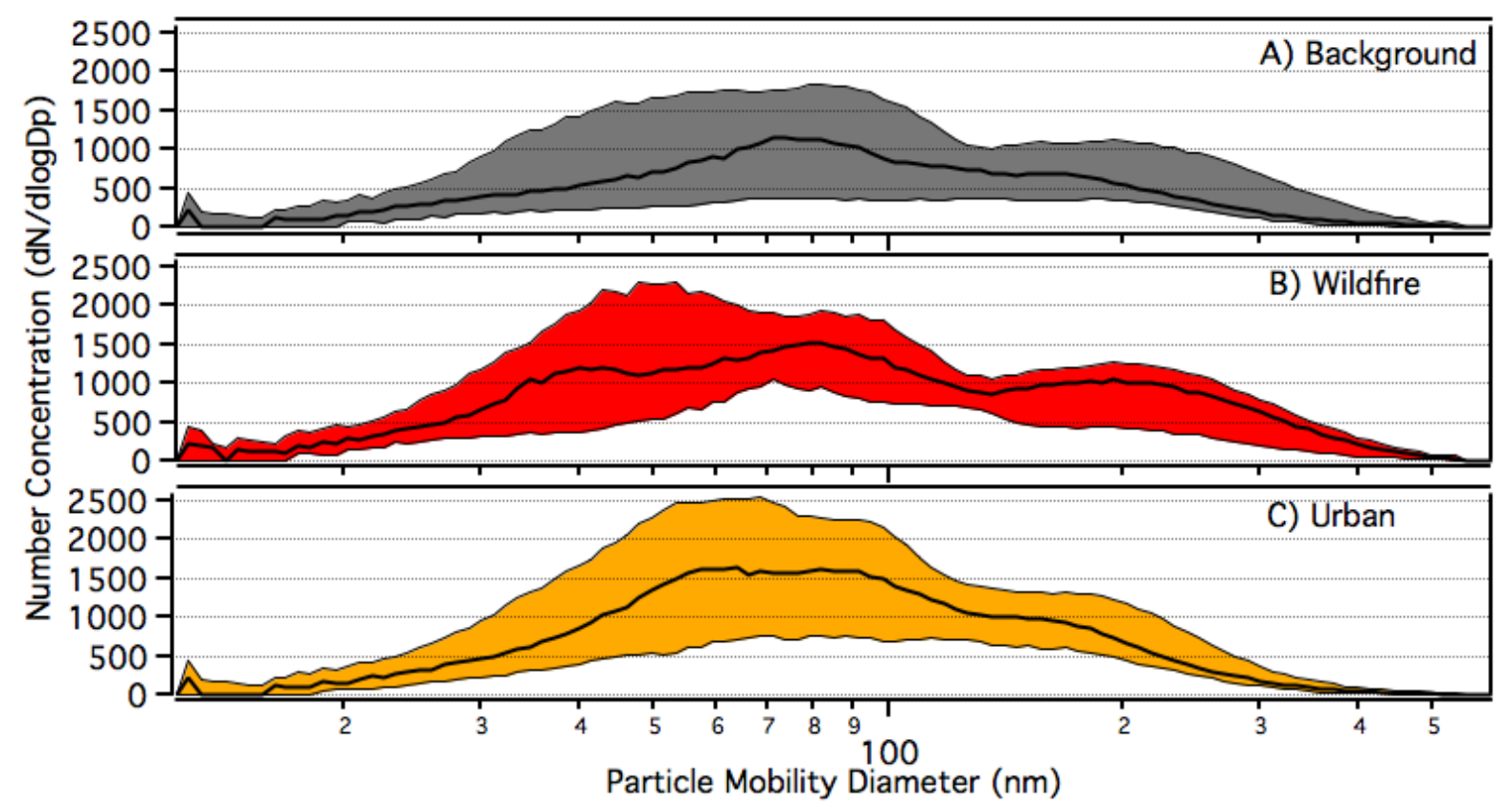

Figure S3. Median and $25^{\text {th }} / 75^{\text {th }}$ percentiles of size-resolved particle number concentration distributions, as measured by SMPS, during the three air mass periods of interest: (A) Background, (B) Wildfire, and (C) Urban. For comparison, particle size distributions by air mass origin at UMBS in summer 2009 were previously discussed in detail by VanReken et al. (2015). 


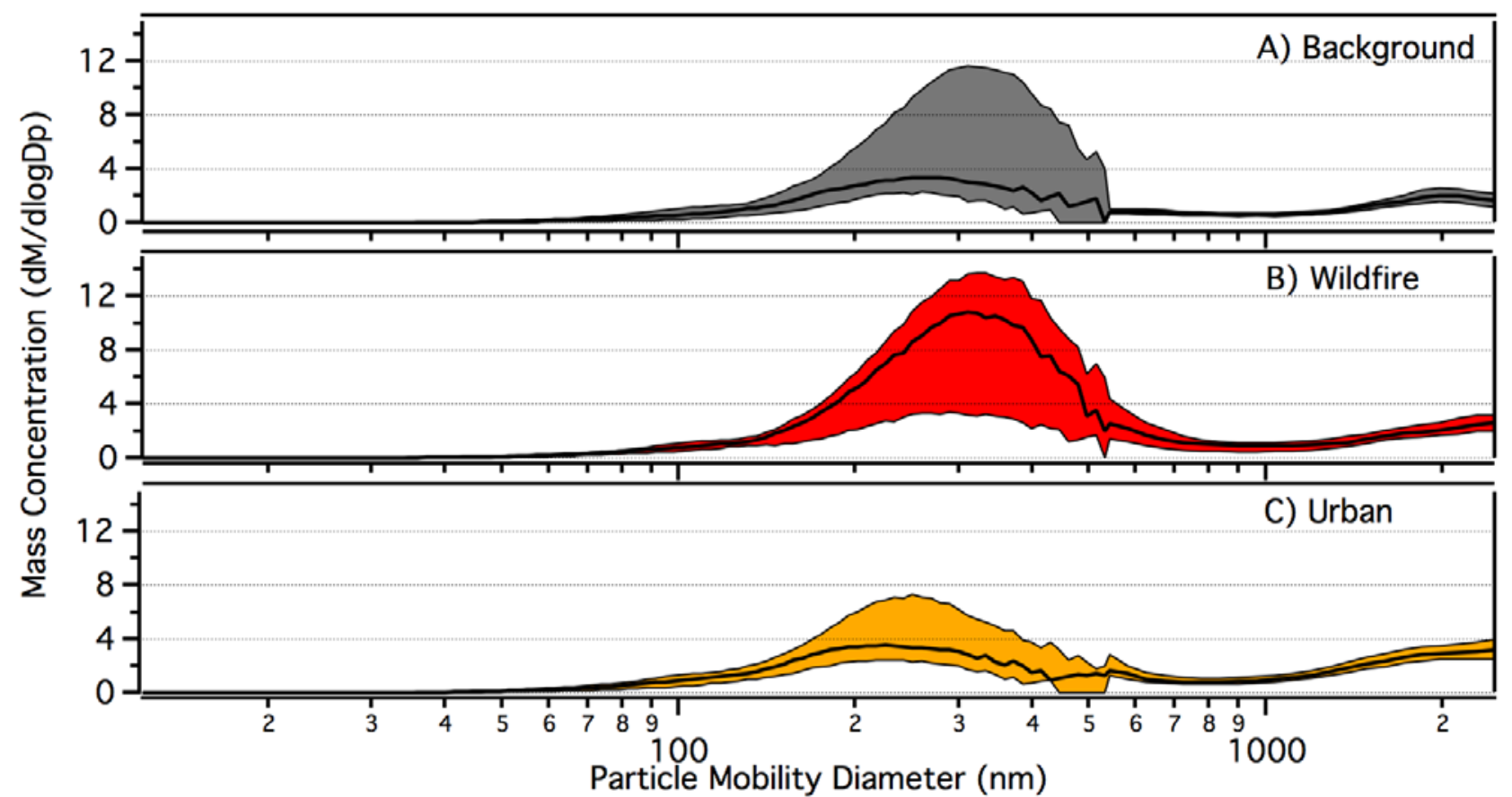

Figure S4. Median and $25^{\text {th }} / 75^{\text {th }}$ percentiles of size-resolved particle mass distributions, as measured by SMPS and APS (assuming a density of $1.5 \mathrm{~g} \mathrm{~cm}^{-3}$ ), during the three air mass periods of interest: (A) Background, (B) Wildfire, and (C) Urban. 


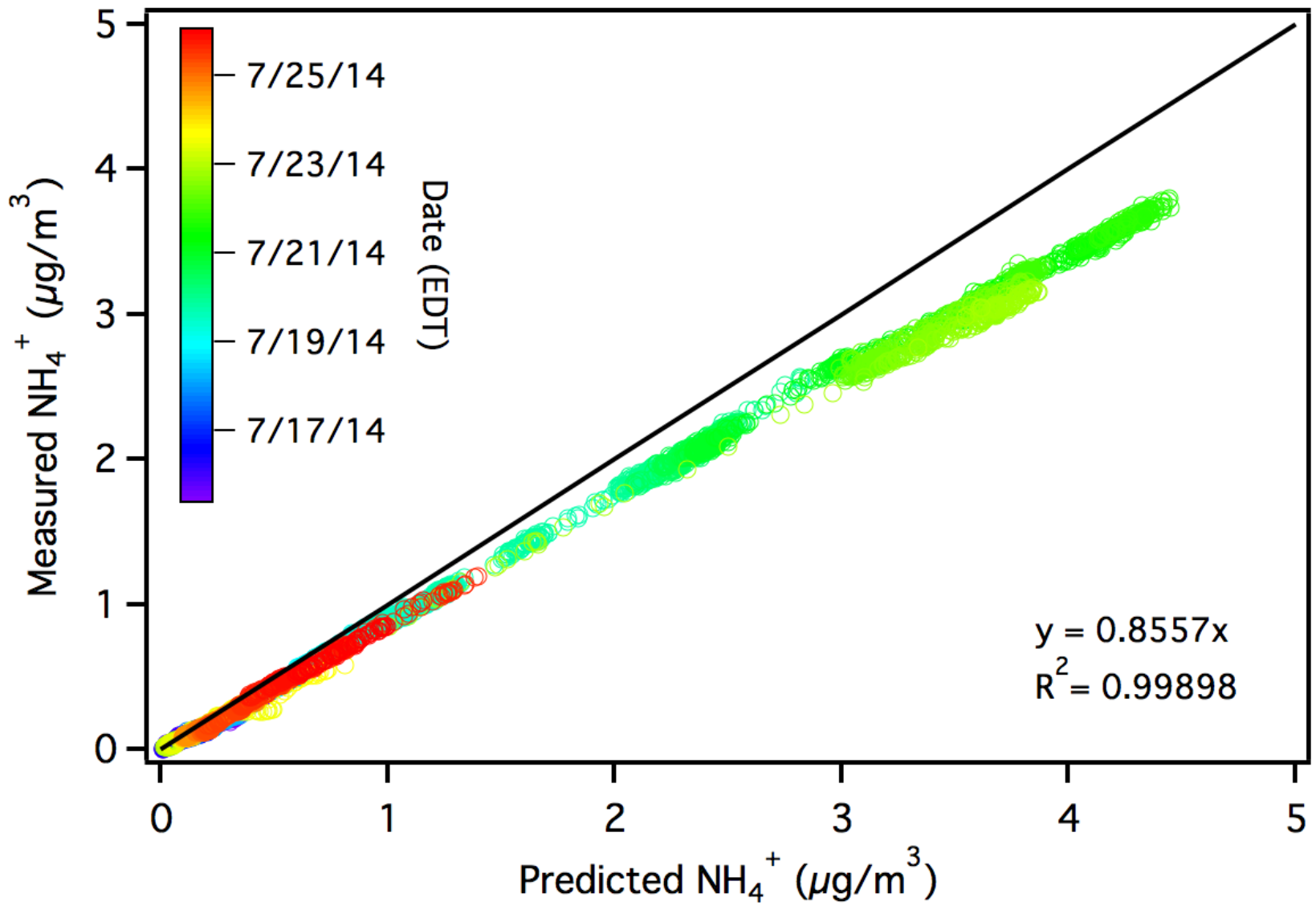

Figure S5. Ammonium balance calculated from predicted ammonium versus measured ammonium from the HR-AMS, following the method of Sueper (2010). A 1:1 line is showed in black for reference. 